\title{
ARTICLE
}

\section{Relationship between Induced Indium Activity and Count Rates of Survey Meters Used to Screen Personnel Exposed in Criticality Accidents}

\author{
Chie TAKADA*, Takahiro NAKAGAWA, and Norio TSUJIMURA \\ Japan Atomic Energy Agency, Tokai, Naka, Ibaraki 319-1194, Japan
}

\begin{abstract}
Small pieces of indium foil have been universally adopted by many nuclear facilities for the purpose of screening personnel exposed in criticality accidents because any neutron-induced activity of indium foil can be measured with survey meters. The authors performed experiments in which the counting efficiency of a survey meter to radiation from activated indium foil was evaluated using a ${ }^{252} \mathrm{Cf}$ neutron source. In those experiments pieces of indium foil were irradiated outside an aluminum tube containing a ${ }^{252} \mathrm{Cf}$ source, all of which was placed inside an annular PMMA cylinder moderator. The count rates to indium activity were then measured with a portable GM survey meter. Reference values of the activity of ${ }^{115 \mathrm{~m}}$ In and ${ }^{116 \mathrm{~m}}$ In were evaluated using measurements with a germanium detector and MCNP-4C2 calculations, resulting in the counting efficiency of a survey meter being evaluated to be $0.6 \%$. This result then allowed appropriate doses to be converted from the count rates to be applied in the screening procedure.
\end{abstract}

KEYWORDS: indium, criticality accident, neutron, screening, GM survey meter, Monte Carlo calculation

\section{Introduction}

While the occurrence of criticality accidents has been extremely rare at nuclear facilities personal dosimetry procedures for assessing doses from an event still need to be established. The procedures consist of several steps. The first step to be taken immediately after the occurrence of an event is a screening which identifies anybody that has been irradiated and then sorts them in descending order of their degree of exposure from most severely irradiated to least. Anybody judged to have been seriously exposed can then be placed under medical care.

Small pieces of indium foil incorporated into personal dosimeters or ID badges have been widely adopted at many nuclear fuel facilities for this very purpose. ${ }^{1)-3}$ etc. Indium has a high thermal neutron capture cross-section, with the activation product of ${ }^{116 \mathrm{~m}}$ In emitting beta and gamma rays with a half-life of 54 minutes being readily detectable with portable GM-type survey meters. The survey meter indication, typically in units of counts per minute (cpm or $\left.\mathrm{min}^{-1}\right)$, is a measure of level of exposure. While the screening measurements often do not necessitate great accuracy the criteria used in the screening needs to be based on the dose level at which further action should be taken. This procedure is typically accomplished using the relationship between the meter indication and the exposure dose, i.e., "cpm-dose relationship", that can be directly assessed through reactor irradiation experiments.

To date the Nuclear Fuel Cycle Engineering Laboratories (NCL) of the Japan Atomic Energy Agency (JAEA) has carried out a limited number of calibration experiments using the reactors: the initial tests that were carried at the Nuclear Safety Research Reactor (NSRR) of JAEA in the $1980 \mathrm{~s}^{4}$ and more recent reassessment tests carried out at the SILENE reactor of the Valduc center of the Commissariat à l'Energie

*Corresponding Author, Tel: +81-29-282-1111, Fax: +81-29-282

-9382, E-mail:takada.chie@jaea.go.jp
Atomique (CEA). ${ }^{5)}$ The latter tests in particular provided a very realistic simulation of a probable process-line criticality accident. In order to summarize the above experimental data and update the cpm-dose relationship so as to extensively encompass any exposure condition likely to occur in an accidental criticality event, we need supplemental data on the detector's counting efficiency or "activity-cps relationship", which is essentially independent of neutron energy and can only be determined from measurement conditions such as counting geometry. This paper therefore describes experiments in which the counting efficiency of a GM detector to radiation from indium foil was evaluated using a ${ }^{252} \mathrm{Cf}$ neutron source.

\section{Materials and Methods \\ 1. Indium Foil}

A photo of a personal dosimeter in use at NCL by radiation workers is given in Fig. 1. The dosimeter (referred to as a TLD badge) is composed of Panasonic Model UD-808P and UD-809P thermoluminescence dosimeters inside a plastic hanger. The UD-808P detects beta and gamma rays while the UD-809 detects neutrons, which is therefore placed at the left of the hanger where the cadmium shield is positioned. A piece of indium foil (size: $10 \times 4.5 \times$ $1.2 \mathrm{~mm}^{3}$, weight: $360 \mathrm{mg}$ ) is set in the internal slot of the hanger.

Indium foil is used for two purposes. First, ${ }^{116 \mathrm{~m}}$ In activity, which is produced through the ${ }^{115} \mathrm{In}(n, \gamma){ }^{116 \mathrm{~m}} \mathrm{In}$ reaction predominantly with thermal neutrons, can be used in the above mentioned screening. Indium- $116 \mathrm{~m}$ emits some energetic beta-rays at $1,010 \mathrm{keV}$ ( $52.1 \%$ abundance), 872 $\mathrm{keV}(33.8 \%)$ etc and gamma-rays at $1,294 \mathrm{keV}(84.4 \%)$, $1,097 \mathrm{keV}$ (56.2\%), $417 \mathrm{keV}$ (27.7\%), 2,112 keV (15.5\%) etc. Hence, the screening measurements provided by a GM survey meter can also be done without having to remove the indium foil from the badge itself. 
Another purpose is for fast neutron dose evaluation. In addition to ${ }^{116 \mathrm{~m}} \mathrm{In},{ }^{115 \mathrm{~m}} \mathrm{In}$ activity with a half-life of $4.5 \mathrm{~h}$ is produced in ${ }^{115} \operatorname{In}\left(n, n^{\prime}\right)^{115 \mathrm{~m}}$ In reactions with threshold reactions (effective energy of $1.5 \mathrm{MeV}$ ). Indium- $115 \mathrm{~m}$ emits gamma-rays at $336 \mathrm{keV}(45.8 \%$ abundance $)$. As part of a dosimetry procedure subsequent to the screening the foil can be removed from the badge and used for fast neutron dosimetry via high-resolution gamma spectrometer measurements.

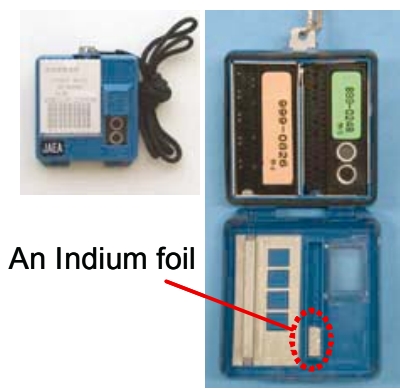

Fig. 1 NCL personal thermo-luminescence dosimeter, showing the position of the indium foil with the case opened.

\section{Experiment Irradiation Setup}

The indium foil was irradiated with neutrons in the Instrument Calibration Facility (ICF) low-scatter room at NCL using a specially moderated ${ }^{252} \mathrm{Cf}$ source.

The experimental setup is given schematically in Fig. 2, although it is not to scale. It indicates how the source and PMMA (polymethyl methacrylate) moderator were positioned so as to provide slow neutrons as well as fast neutrons at high intensity and thereby simultaneously produce significant amounts of ${ }^{116 \mathrm{~m}} \mathrm{In}$ and ${ }^{115 \mathrm{~m}} \mathrm{In}$. Indium foils were placed on the circumference of an aluminum tube (external diameter of $40 \mathrm{~mm}$ ) into which the ${ }^{252} \mathrm{Cf}$ source is pneumatically transferred. Three foils were arrayed in 4 positions at $90^{\circ}$ intervals and a laser alignment system was used to ensure that their effective vertical center levels coincided with the ${ }^{252} \mathrm{Cf}$ source. In addition, an annular PMMA cylinder moderator (100 $\mathrm{mm}$ in thickness) was used to encircle the tube and thus provide more neutron moderation. Photos of the experimental irradiation setup are provided in Fig. 3. The irradiation source was positioned at a height of $1.26 \mathrm{~m}$ from the steel grating floor of the room. Details on this apparatus are provided elsewhere. ${ }^{6}$ )

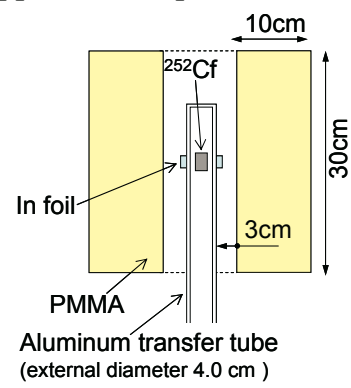

Fig. 2 Schematic diagram of the experimental setup.

(Diagram is not to scale.)

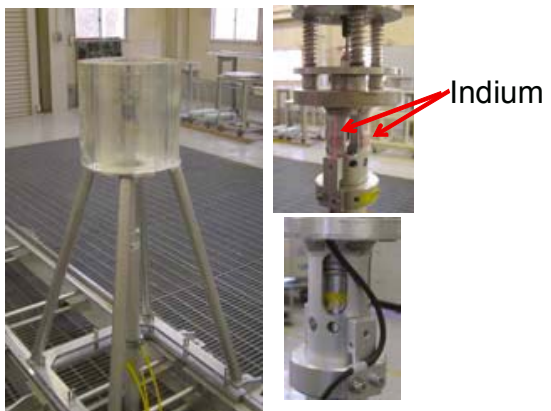

Fig. 3 Experimental indium irradiation setup Left: General view,

Upper Right: Expanded view showing indium foils taped to the surface of the source transfer aluminum tube,

Lower Right: Expanded view of the source position (with an imitation capsule in place.)

A ${ }^{252} \mathrm{Cf}$ source with an emission rate of $1.6 \times 10^{7}$ neutrons per sec was used. An irradiation time of 8 hours delivered an integral tissue kerma of approx. 0.3 Gy over the foil volume. It should be noted that while this situation does not depict an actual accident it does not affect the experimental determination of the activity-count rate relationship.

\section{GM Measurements}

Prior to the measurements one of the irradiated indium foils was reset in the badge case. The badge - GM detector placement used in the measurement is given in Fig. 4. The measurements were made using an Aloka Corporation end-window GM Probe survey meter (Model TGS-113) with the following specifications:

- Outer diameter of window: $50 \mathrm{~mm}$

- Size of incidence area: approx. $19.6 \mathrm{~cm}^{2}$ (aperture ratio: approx. $85 \%$ )

- Thickness of window: approx. $2.5 \mathrm{mg} / \mathrm{cm}^{2}$

The entry window of the detector was set upon the surface of the projecting part of the badge case in a constant-geometry holder, which was improvised using 50 -mm-thick lead block walls and a ring-stand to hold the tube. The distance from the entry window to the indium foil in the badge case was about $10 \mathrm{~mm}$. Following the screening measurement procedure the center of the GM window was then set to the center-line of the badge, although the position of the indium foil was not exactly at the geometric center of the badge case.
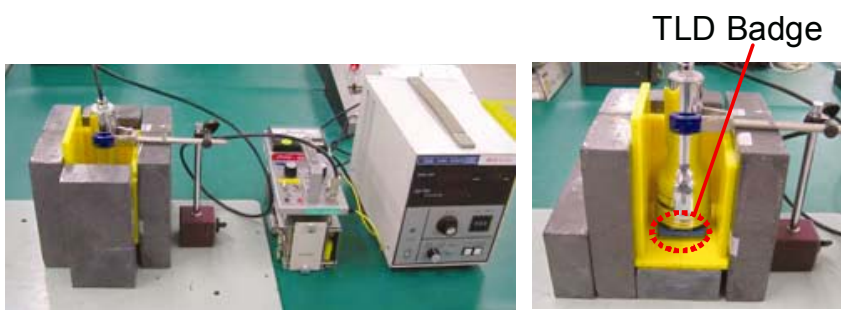

Fig. 4 GM measurement setup showing lead block-walled assembly holding the GM probe and the badge sample, survey meter and scaler.

(Left: arrangement of scaler, survey meter and GM probe, Right: inside the lead shield.) 
The output of the GM detector was connected to a scaler and the counts accumulated over 3 minutes. Measurement commenced straight after the irradiation had completed. All the results of the measurements were then decay-corrected to a reference time on completion of irradiation.

\section{Activity Evaluation}

Reference values for the activity of ${ }^{116 \mathrm{~m}}$ In and ${ }^{115 \mathrm{~m}}$ In were evaluated using gamma spectrum measurements made using a germanium detector and Monte Carlo calculations using MCNP-4C2.

(1) $\mathrm{HP}-\mathrm{Ge}$

The counts were made using a HP-Ge spectrometry system (ORTEC GMX50-S) housed in a shield room composed of 200-mm thick iron, 3-mm thick lead, 0.5-mm thick copper, and 3-mm thick vinyl chloride. The high resolution of the system allowed simultaneous analysis of the activity of both ${ }^{116 \mathrm{~m}}$ In and ${ }^{115 \mathrm{~m}}$ In.

The specifications of the detector are as follows:

- Detector: n-type germanium semiconductor

- Relative efficiency: $50 \%$

- Detectable energy region: $10-2000 \mathrm{keV}$

- Size of the Ge crystal: $3000 \mathrm{~mm}^{2} \times 70 \mathrm{~mm}(\mathrm{~L})$

- Distance between the end-cap and crystal: $4 \mathrm{~mm}$

- End-cap material: beryllium

Before the experiments the counting efficiencies were calibrated using the four plate-shape gamma-ray sources of ${ }^{241} \mathrm{Am},{ }^{133} \mathrm{Ba},{ }^{137} \mathrm{Cs}$ and ${ }^{60} \mathrm{Co}$. The counting efficiencies to gamma rays of ${ }^{116 \mathrm{~m}} \mathrm{In}$ and ${ }^{115 \mathrm{~m}} \mathrm{In}$ were determined through an interpolation using a smooth efficiency curve derived from the spectroscopy software bundled with the measurement system. Indium foil or calibration sources were placed on a 5 -mm-thick plastic plate positioned at a distance of $0.25 \mathrm{~m}$ from the entrance window of the HP-Ge.

Measurement commenced about 10 minutes after completion of the irradiation and then the data amassed over 14 hours. All the results of the measurements were decay-corrected to a reference time upon completion of the irradiation according to the Eq. (1).

$$
C=\varepsilon \times A_{M} \times\left(e^{-\lambda \times T_{1}}-e^{-\lambda \times T_{2}}\right) / \lambda
$$

where $A_{M}$ is the activity at the end of irradiation (Bq), $C$ is the peak counts, $\lambda$ is the decay constant $\left(\mathrm{s}^{-1}\right)$ of the nuclide, $\mathrm{T}_{1}$ is the time from the end of irradiation $(\mathrm{t}=0)$ to start of measurement ( $\mathrm{sec}), \mathrm{T}_{2}$ is the time from the end of irradiation $(\mathrm{t}=0)$ to end of measurement $(\mathrm{s})$, and $\varepsilon$ is the detection efficiency.

\section{(2) Monte Carlo Calculations}

The amount of ${ }^{116 \mathrm{~m}} \mathrm{In}$ and ${ }^{115 \mathrm{~m}}$ In activity for the irradiation configurations were calculated using MCNP-4C Monte Carlo computer code. ${ }^{7)}$ The nuclear data library used was from JENDL-3.2 ${ }^{8)}$ and the dosimetry data from JENDL/D-99. ${ }^{9)}$

The ${ }^{252} \mathrm{Cf}$ source, aluminum transfer tube, the electromagnet that held the source capsule in place and the moderator etc were modeled using available designs to be as accurate as possible. The adequacy of the calculation model was verified in an evaluation study of the anisotropy of the ${ }^{252} \mathrm{Cf}$ source with the irradiation apparatus. ${ }^{10)}$ The thermal neutron cross sections $S(\alpha, \beta)$ of hydrogen within polyethylene were used for the hydrogen in the PMMA because of the similar chemical binding of $\mathrm{H}-\mathrm{C}-\mathrm{H}$. The source spectrum of ${ }^{252} \mathrm{Cf}$ was taken from ISO8529-1 ${ }^{11)}$ and the neutrons were generated as a volume source with isotropic direction.

The number of ${ }^{115} \operatorname{In}(n, \gamma){ }^{116 \mathrm{~m}} \mathrm{In}$ and ${ }^{115} \operatorname{In}\left(n, n^{\prime}\right)^{115 \mathrm{~m}} \mathrm{In}$ reactions in the indium foil were tallied using track-length estimates (F4 in MCNP) and the multiplier of their microscopic cross-sections. The output of the F4 tally denoted the number of reactions per unit volume normalized to the neutron emission from the ${ }^{252} \mathrm{Cf}$ source capsule region. The reaction rate, therefore, was obtained by multiplying the output with the volume of the foil and the emission rate of the neutrons on the date of the experiment. While the irradiation time of 8 hours was enough to allow the ${ }^{116 \mathrm{~m}} \mathrm{In}$ to become saturated it was not the case with ${ }^{115 \mathrm{~m}} \mathrm{In}$. The rate of decay of ${ }^{115 \mathrm{~m}}$ In during irradiation was thus compensated for in order to obtain the activity at time zero, i.e., the end of irradiation according to the Eq. (2).

$$
A_{c}=R \times V \times\left(1-e^{-\lambda T}\right) \times B
$$

where $\mathrm{R}$ is the calculated reaction rate per unit volume at one neutron emission $\left(\mathrm{cm}^{-3}\right), \lambda$ is the decay constant of the nuclide $\left(\mathrm{s}^{-1}\right), \mathrm{V}$ is the volume of the peaces of the indium foil $\left(\mathrm{cm}^{3}\right), \mathrm{T}$ is the irradiation time $(\mathrm{s})$, and $\mathrm{B}$ is the neutron emission rate $\left(\mathrm{s}^{-1}\right)$.

\section{Results and Discussion}

The calculated and measured activity of ${ }^{116 \mathrm{~m}}$ In and ${ }^{115 \mathrm{~m}}$ In and the counts rate measured with the GM survey meter are summarized in Table 1. The counting efficiency, defined as the ratio of the count-rate to activity, is also presented in the right column of the table. The values of the induced activity of both ${ }^{116 \mathrm{~m}} \mathrm{In}$ and ${ }^{115 \mathrm{~m}} \mathrm{In}$ evaluated using HP-Ge spectrometry measurements and MCNP calculations coincide with each other. As both the measurements and the calculations were independently made this good agreement demonstrates the activity evaluations to have been appropriate. In addition, two factors seem to have greatly contributed to that favorable result. The first is that because of the symmetrical experimental configuration uncertainties due to small misalignments of the source and indium foil could be corrected by averaging the measured results. The second is that as the PMMA moderator acted as an enclosure and the large room dimensions contributed to well-controlled production of thermal neutrons and the suppression of uncontrolled room scatter, respectively, the uncertainties that had not been considered in the MCNP calculation model could be excluded. 
Table 1 Summary of the results measured and calculated results

\begin{tabular}{|c|c|c|c|c|}
\hline \multirow[b]{2}{*}{ Isotope } & \multicolumn{2}{|c|}{ Induced Activity } & \multirow{2}{*}{$\begin{array}{c}\text { Survey } \\
\text { meter } \\
\text { Count } \\
\text { M [cpm] }\end{array}$} & \multirow{2}{*}{$\begin{array}{c}\text { Counting } \\
\text { Efficiency } \\
\mathrm{M} / \mathrm{A}_{\mathrm{C}} \\
{[\%]}\end{array}$} \\
\hline & $\begin{array}{c}\text { Calculation } \\
\mathrm{A}_{\mathrm{C}}[\mathrm{Bq}]\end{array}$ & $\begin{array}{c}\text { Measurement } \\
\mathrm{A}_{\mathrm{M}}[\mathrm{Bq}]\end{array}$ & & \\
\hline${ }^{115 \mathrm{~m}} \mathrm{In}$ & 82 & 78 & \multirow{2}{*}{$\left.1.8 \mathrm{E}+03^{*}\right)$} & \multirow{2}{*}{0.6} \\
\hline${ }^{116 \mathrm{~m}} \mathrm{In}$ & $6.4 \mathrm{E}+04$ & $6.7 \mathrm{E}+04$ & & \\
\hline $\begin{array}{l}{ }_{116 \mathrm{~m}} \mathrm{In} / \\
{ }^{115 \mathrm{~m}} \mathrm{In}\end{array}$ & 780 & 860 & --- & --- \\
\hline
\end{tabular}

*) Note that the count rate from the bare indium foil was $5 \mathrm{kcpm}$, or 2 - 3 times greater than this value, indicating the shielding effect of the badge case to radiation emitted from ${ }^{116 \mathrm{~m}} \mathrm{In}$.

The reference activity of activated indium was adopted as the average of the two values of the HP-Ge measurement and the MCNP calculation. Considering the ratio between ${ }^{116 \mathrm{~m}} \mathrm{In}$ and ${ }^{115 \mathrm{~m}} \mathrm{In}$, the majority of the counts of the GM detector came from ${ }^{116 \mathrm{~m}} \mathrm{In}$, namely it evaluates the dose attributed to thermal neutrons. The counting efficiency was evaluated to be $0.6 \%$, with a standard uncertainty of $12 \%$, which was evaluated from the statistical uncertainty in the GM measurements $(<5 \%)$, the standard deviations in counts rates from multiple indium samples $(<5 \%)$, and the uncertainty in reference activity directly derived from the deviation between $A_{C}$ and $A_{M}$. Assuming a total dose of 10 mGy to be roughly $10 \mathrm{kBq}$ per gram of indium in a typical criticality accident ${ }^{12)}$ results in the specific combination of the TLD badge and GM survey meter providing a reading of 1300 cpm per $10 \mathrm{mGy}$. Considering the wide variation in the indium activity to the neutron spectrum, this response does not contradict that of the $\sim 2 \mathrm{kcpm}$ per $10 \mathrm{mGy}$ experimentally obtained in the SILENE experiments. ${ }^{13)}$

\section{Summary}

In order to reconfirm the NCL's screening procedures for highly exposed personnel in a criticality accident, experiments were made in which the counting efficiency of a GM detector to radiation from indium foil was evaluated using a ${ }^{252} \mathrm{Cf}$ neutron source. The relationship between the induced activity of indium foil in a TLD badge case and the count rates of a GM survey meter was evaluated to be $0.6 \%$. This result supports the triangular interrelation between activity, cpm and dose applied to badges used in screening in criticality accidents being derivable with the help of spectrum computations under any reasonably-assumable accident scenario.

\section{Acknowledgment}

The authors wish to acknowledge Messrs. T. Yoshida and Y. Terakado for their assistance with the measurements.

\section{References}

1) For example: International Atomic Energy Agency, Dosimetry for Criticality Accidents - A Manual, IAEA Technical Report Series No.211 (1982).

2) M. T. Ryan et al., Calibration of the indium foil used for criticality accident dosimetry in the UCC-ND employee identification badge, ORNL/TM-8294, Oak Ridge national Laboratory (1982).

3) R. E. Swaja and R. Oyan, "Uncertainties associated with using quick-sort techniques to estimate neutron doses following criticality accidents," Health Phys., 52[1], 65-68 (1987).

4) K. Koizumi, K. Miyabe, Y. Nomura, et al., PNC-TN841 85-07, Power Reactor and Nuclear Fuel Development Corporation (1985), [in Japanese].

5) R. Médioni, B. Asselineau, B. Verrey, et al., "Criticality accident dosimetry systems: an international intercomparison at the silene reactor in 2002," Radiat. Prot. Dosim., 110, 429-436 (2004).

6) N. Tsujimura, T. Yoshida, "Characteristics of the simulated workplace neutron fields using a ${ }^{252} \mathrm{Cf}$ source surrounded with cylindrical moderators", Radiat. Prot. Dosim., 110, 117-121 (2004).

7) F. Briesmeister (Ed)., MCNP A General Monte Carlo $N$-Particle Transport Code Version 4C, LA-13709-M, Los Alamos National Laboratory, (2000).

8) K. Shibata, T. Kawano, T. Nakagawa, et al., "Japanese Evaluated Nuclear Data Library Version 3 Revision-3: JENDL-3.3," J. Nucl. Sci. Technol. 39[11], 1125-1136 (2002).

9) K. Kobayashi, T. Iguchi, S. Iwasaki, et al., JENDL Dosimetry File 99 (JENDL/D-99), JAERI 1344, Japan Atomic Energy Research Institute (2002).

10) N. Tsujimura, T. Yoshida and T. Momose, "Calculations of anisotropy factors for radionuclide neutron sources due to scattering from source encapsulation and support structures," Radiat. Prot. Dosim., 126, 168-173 (2007).

11) International Organization for Standardization, "Reference neutron radiations - Part 1: Characteristics and method of production", ISO 8529-1 (2001).

12) H. J. Delafield, "Nuclear Accident Dosimetry", Radiat. Prot. Dosim., 10, 237-249 (1985).

13) Japan Atomic Energy Agency, Annual Report on the Present State and Activities of the Radiation Protection Department, Nuclear Fuel Cycle Engineering Laboratories in Fiscal 2007, JAEA Review 2008-071, 84-85, (2009), [in Japanese]. 